\title{
Farmer's intended and actual adoption of climate change mitigation and adaptation strategies
}

\author{
Meredith T. Niles ${ }^{1,2}$ (D) Margaret Brown ${ }^{3} \cdot$ \\ Robyn Dynes ${ }^{4}$
}

Received: 27 May 2015 / Accepted: 6 November 2015 / Published online: 16 November 2015

(C) The Author(s) 2015. This article is published with open access at Springerlink.com

\begin{abstract}
A growing body of work aims to understand the impacts of climate change on agriculture as well as farmer's perceptions of climate change and their likeliness to adopt adapting and mitigating behaviors. Despite this, little work has considered how intention to adopt differs from actual adoption of climate change practices in agriculture. Applying the Theory of Planned Behavior we aim to assess whether different factors affect intended versus actual adoption of climate behaviors among farmers in New Zealand. Data were collected through mixed methods (37 interviews and a telephone survey of 490 farmers) in two regions of New Zealand 2010-2012. Through multiple regression models we test hypotheses related to the Theory of Planned Behavior around the role of attitudes, subjective norms, and perceived capacity in affecting intended and actual adoption. Results suggest that there are different drivers of intended and actual adoption of climate change practices. Climate change attitudes and belief is only associated with intended not actual adoption. We find no evidence that subjective norms (climate change policy support) significantly influence either intention or actual adoption. Only perceived capacity and self-efficacy were important predictors of both
\end{abstract}

Electronic supplementary material The online version of this article (doi:10.1007/s10584-015-1558-0) contains supplementary material, which is available to authorized users.

Meredith T. Niles

mtniles@uvm.edu

Margaret Brown

margaret.brown@agresearch.co.nz

Robyn Dynes

robyn.dynes@agresearch.co.nz

1 Department of Nutrition and Food Sciences and Food Systems Initiative, University of Vermont, 109 Carrigan Drive, 350 Marsh Life Sciences Building, Burlington, VT 05405, USA

2 Sustainability Science Program, Kennedy School of Government, Harvard University, 79 JFK Street, Mailbox 81, Cambridge, MA 02138, USA

3 Grasslands Research Centre, Private Bag AgResearch Ltd., Private Bag 11008, Palmerston North 4442, New Zealand

4 Lincoln Research Centre, AgResearch Ltd., Lincoln, New Zealand 
intended and actual adoption. These results suggest a disconnect between intended and actual behavior change and that using data about intention as a guiding factor for program and policy design may not be prudent. Furthermore, fostering perceived capacity and self-efficacy for individuals may be crucial for encouraging both intended and actual adoption of climate adapting and mitigating behaviors.

\section{Introduction}

In recent years, agricultural science, innovation and development has shifted to include a focus on climate change. Agriculture's contribution to global greenhouse gas (GHG) emissions at $14 \%$ of total emissions (and up to $25 \%$ including related land-use changes) (Smith et al. 2014) as well as its potential to be heavily affected by changing temperatures, water availability and extreme events make it an important focus for climate change action (Challinor et al. 2014). Efforts to understand how farmers perceive climate change and may respond have been particularly focused in developing countries (Wood et al. 2014; Kristjanson et al. Bryan et al. 2009; Seo and Mendelsohn 2008) especially in the context of food security and production. However, there is growing attention on assessing developed country farmers' perspectives on climate change and their responses (Prokopy et al. 2015; Niles et al. 2015; Arbuckle et al. 2014; Niles et al. 2013; Haden et al. 2012; Barnes and Toma 2012). This work is crucial to assess both at a case study level (Niles et al. 2015; Arbuckle et al. 2014; Haden et al. 2012) and across broader contexts (Wood et al. 2014) to determine drivers of climate mitigation and adaptation behaviors.

To date, the majority of existing studies examining farmer's perspectives and responses to climate change either measure likelihood to adopt a practice, support mitigation and adaptation initiatives in the future (Niles et al. 2013, 2015; Arbuckle et al. 2013) or examine the actual adoption of a practice (Wood et al. 2014; Kristjanson et al. 2012). Very few studies have aimed to determine how intention to adopt a behavior differs from actual adoption, and whether different factors drive intended and actual behavior. Despite this, a large body of work in psychology suggests that there may be significant differences between intended and actual behavior (Ajzen 1991). This paper aims to fill this literature gap by determining the factors that influence farmer's intended and actual adoption of climate change mitigation and adaptation practices ("climate change practices" (CCP)) among farmers in New Zealand, where agriculture is a significant contributor to national emissions.

\section{Theoretical grounding}

\subsection{Diffusion and adoption of agricultural innovations}

There is a long standing body of literature that aims to assess the drivers of adoption of practices in an agricultural context. Beginning with early seminal work from Ryan and Gross (1943) to understand the diffusion and adoption of hybrid corn, agricultural researchers have spent decades trying to evaluate the uptake of agricultural innovations. Of the many existing studies many have been based on understanding the adoption or rejection of a single technology such as rBST (Barham et al. 2004; Barham 1996), nitrogen tests and application controls (Barnes et al. 2009; Contant and Korsching 1997) and drip irrigation (Garb and Friedlander 2014). Others have looked broadly at conservation practices in agriculture (Reimer 
et al. 2013; Greiner and Gregg 2011; Delgado and Bausch 2005; Fuglie and Kascak 2001). The diffusion of innovation theory (Rogers 2003) suggests that an innovation diffuses over time based on characteristics of the innovation itself, the social context, and the communication channels in which the innovation are spread. Since these vary significantly based on both the innovation and the place, many have concluded that there are no universal predictors for behavior change in agriculture (Prokopy et al. 2008; Knowler and Bradshaw 2007). As such, place-based studies are a useful way in which to assess drivers of adoption for a given context and to test the applicability of existing theory in different regions.

\subsection{Theory of planned behavior and climate behaviors}

The Theory of Planned Behavior (TPB) is a psychological theory that suggests that behavioral intentions are driven by beliefs and attitudes toward the behavior, subjective norms, and perceived behavioral control (the perceived ability that an individual can actually change behavior). These factors aggregate to develop intention to adopt a behavior, but actual behavioral control acts as a mediator between intention to change behavior and actual behavior change (Ajzen 1991). Perceived behavioral control is related to the concept of self-efficacy defined by Bandura (1986) as "a judgement of one's capability to accomplish a certain level of performance." Assessing intention to perform a behavior versus actual adoption of that behavior is important as many studies ask individuals about their intention to adopt a new practice as a proxy for actual behavior change. In practice, though many people have the intention to do something they may not; thus understanding these discrepancies can ensure that policies and interventions are not misinformed and ineffective.

\section{New Zealand context and hypotheses}

\subsection{New Zealand and climate change}

In the last century New Zealand average temperatures increased by $0.9^{\circ} \mathrm{C}$ and are expected to rise on average between 0.2 to $2.0^{\circ} \mathrm{C}$ by 2040 and 0.7 to $5.1^{\circ} \mathrm{C}$ by 2090 . Hawke's Bay and Marlborough are predicted to have increased temperatures ranging from 0.6 to $1.3^{\circ} \mathrm{C}$ by 2040 . By 2090 Hawke's Bay is expected to have increased temperatures of 1.3 to $3{ }^{\circ} \mathrm{C}$ while Marlborough may have temperatures increasing from 1.3 to $2.9{ }^{\circ} \mathrm{C}$ relative to 1990 (Ministry for Environment 2008). Rainfall patterns are expected to trend towards decreasing annual rainfall in the eastern part of the country, including Hawke's Bay and coastal Marlborough, and increasing rainfall in the western parts of the country. Hawke's Bay is expected to see up to a $10 \%$ decrease in annual average rainfall (National Institute for Water and Atmosphere 2008), and droughts are predicted to increase in both regions (Ministry for Environment 2008). Climate impacts will vary by farming system and are explored in greater detail in Clark et al. (2012)

\subsection{New Zealand's emission trading scheme}

In part as a result of existing changes, New Zealand has been at the forefront of climate change policies and research for the past decade. Unlike many other developed 
countries, $47 \%$ of New Zealand's total emissions are from agricultural sources including livestock, manure, and nitrogen fertilizers (New Zealand Ministry for the Environment 2013). As a result, the government began considering options to reduce these emission sources in 2003 with a proposed levy for agricultural mitigation research, which was highly controversial to New Zealand farmers (Fickling 2003). As New Zealand pushed forward on establishing an emissions trading scheme (ETS) it originally proposed including agriculture as a capped source of emissions, which would have required farmers and agricultural processors to pay for the GHGs associated with products and inputs. Currently the ETS only includes $\mathrm{CO} 2$, in part as a result of the agriculture lobby, which lobbied to not include non-CO2 agricultural emissions (Bullock 2012) though agricultural processors are required to report their total emissions. Furthermore, many other sectors including transport, energy, and forestry are now included, which have trickle down impacts on farming in New Zealand (Niles et al. 2015).

New Zealand continues to review the ETS and reconsider the inclusion of non-CO2 gases, which makes this study important for existing policy debates within New Zealand. Furthermore, this work may inform other research and policy development related to non$\mathrm{CO} 2$ emissions in other agricultural regions globally. With this information, policymakers can create better targeted policies that recognize the reductions in GHGs that have already been achieved while also implementing policies that are predicated on promoting the factors that actually influence behavior change.

\subsection{Hypotheses}

Using the TPB as a theoretical grounding for this empirical work, we test whether the TPB holds true in predicting intended and actual adoption of CCPs. Based on the three central tenants of the TPB, we test four hypotheses related to the role of attitudes/ beliefs about the issue and behavior, subjective norms and support for broader societal action, and perceived level of control. We predict: (H1): Climate change belief and risk perceptions will be important predictors of both stated intention and actual adoption. We expect that farmers who believe that climate change is occurring and that humans play a role in the problem will be more likely to intend to adopt and actually adopt CCPs. (H2): Farmer support for climate change and environmental policies will be positively associated with stated and actual adoption. The TPB suggests that subjective norms and the perception of the role of the broader community in dealing with an issue is an important component of intention and actual behavior. In this context, we hypothesize that farmers who support the New Zealand ETS, and the inclusion of agriculture and farmers in that scheme, will be more likely to intend to and actually adopt CCPs. (H3): Behavioral control and perceived capacity will be important predictors of stated and actual adoption. We expect that farmers who have the perceived capacity to change their own behavior and also deal with external impacts from climate change in their farming systems will be more likely to intend to and actually change their behavior. (H4): Farmers who have adopted one type of practice will be more likely to intend to adopt other practices in the future. We hypothesize that farmers who are inherently more likely to change behavior may be "innovators" or "early adopters" as suggested by the diffusion of innovation literature (Rogers 2003) will be more likely to indicate their intention to adopt other practices. 


\section{Methods}

\subsection{Survey and interview methods}

A total of 37 qualitative, semi-structured interviews were conducted in Marlborough and Hawke's Bay regions and with industry representatives in Wellington in 2010 and 2012. Interviewees were farmers across many sectors (sheep, beef, vegetable, horticulture, arable, viticulture, and dairy) as well as with industry representatives and government officials working in agriculture. Interviews were used to inform the development of a telephone survey, which was implemented in August-October 2012 in Marlborough and Hawke's Bay regions. The survey was originally conducted in Yolo County, California in 2011 (Niles et al. 2013; Haden et al. 2012; Jackson et al. 2012). The New Zealand survey was adjusted for local context including practices that were relevant to the region and language.

The telephone survey was implemented with assistance from ResearchFirst, a professional survey company in Christchurch, New Zealand. Farmer databases held by ResearchFirst and census data were utilized as is usual practice with agricultural surveys in New Zealand. The survey was piloted with ten farmers outside of the two target regions. We used a random stratified sample to target farmers to allow for responses within the region to be proportional to the land use type of the areas. A total of 490 farmers responded to the survey with a total response rate of $41 \%(n=177$ in Marlborough, $n=313$ in Hawke's Bay; additional information on response rates and power sample size calculations are in Supplementary Materials).

\subsection{Data analysis and model development}

We used a factor analysis with principle components to determine whether we could aggregate variables that were measuring similar constructs. Factor analyses yielded single factor solutions with factor loadings above 0.40 , which is a generally accepted cut-off point (Costello and Osborne 2005). Table 1 details all of our independent and dependent variables and their respective eigenvalues, factor scores and Cronbach alpha scores. We developed 5 scales as independent variables based on this factor analysis. Belief and attitude (H1) about the behavior and issue is measured by two factors: 1) a farmer's perspective on whether human activities are an important cause of climate change (Climate Change Concern) and 2) Biophysical Concern, which measures concern about potential future biophysical climate change impacts. Subjective norms (H2) are measured through a scale assessing farmer's general perceptions about climate change policies specific to New Zealand and other environmental regulations (Environmental Policy). We have two measures for perceived capacity/behavioral control (H3). We use a farmer's perceived capacity to implement practices that reduce their own GHGs (Local Perceived Capacity) as a proxy that captures local loci of control. We use a farmer's confidence in their ability to adapt to climate change risks (Global Perceived Capacity) as a perceived capacity measure with loci of control and impact outside their own farm system (responding to outside changes and risks).

We also tested for the effect of other factors that have been shown to influence farmer adoption of different types of practices. Contact Scale measures the frequency of contact with organizations, industry representatives, government and other farmers for agricultural information. Profit Adoption encompasses production and cost driven 


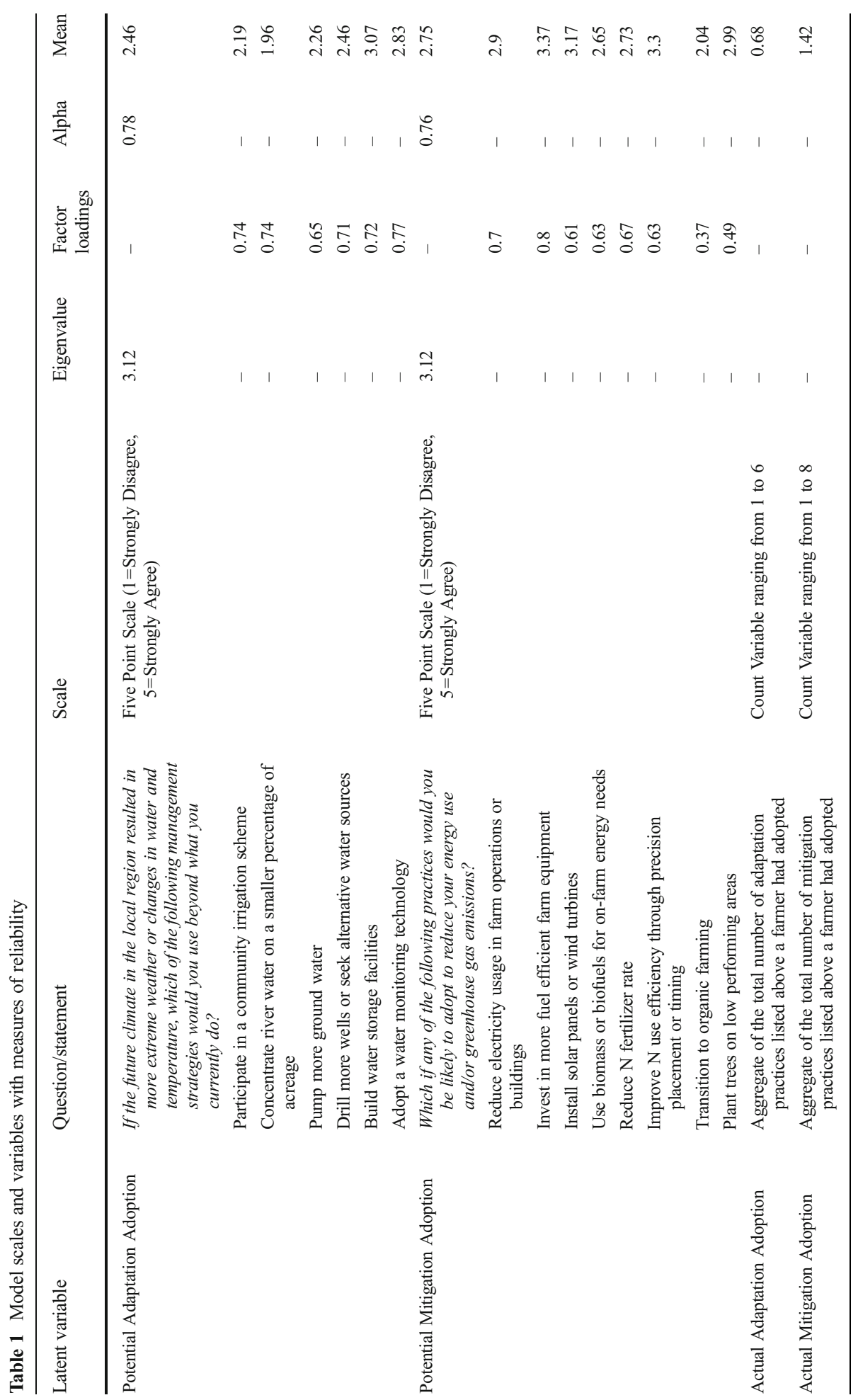




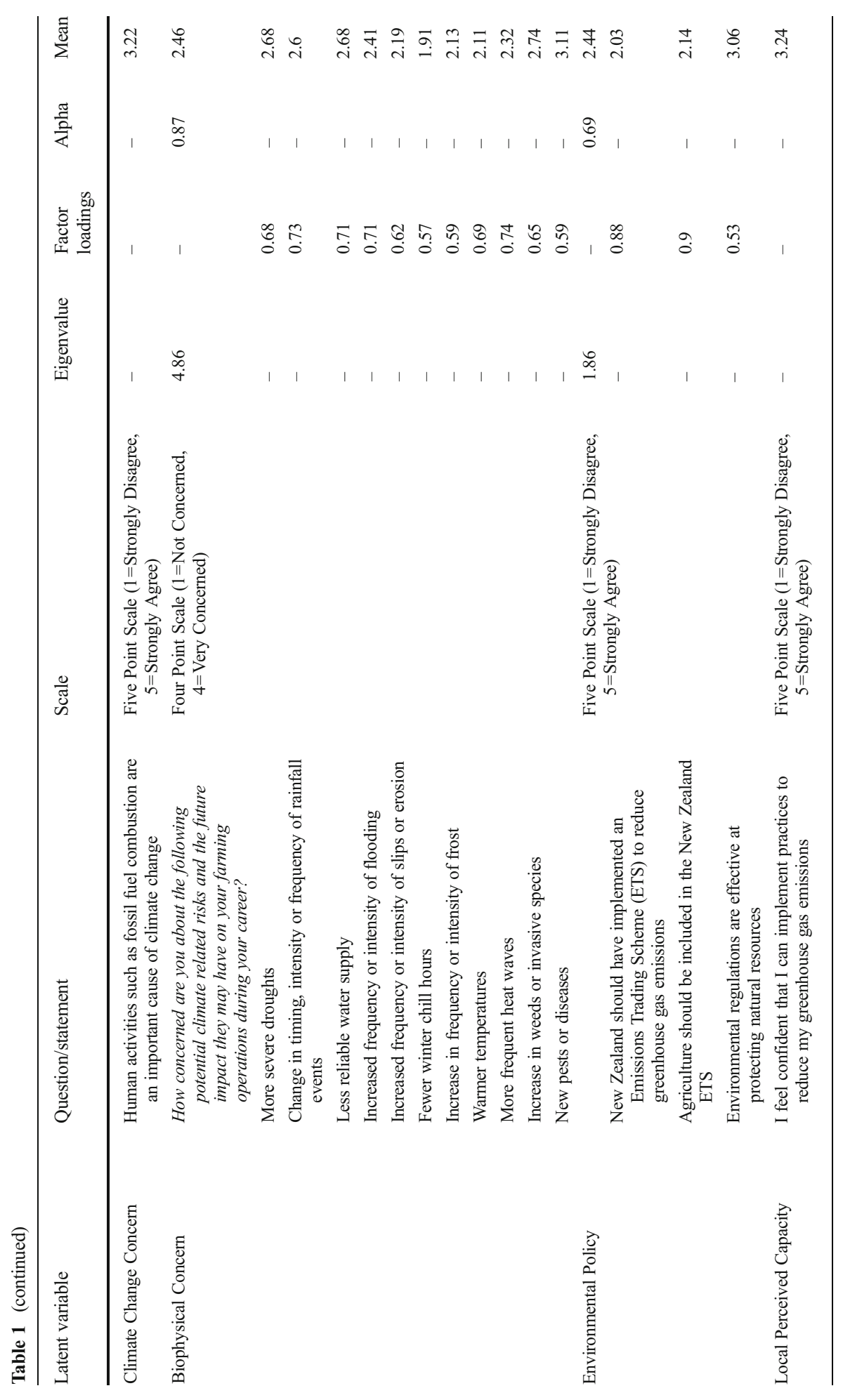




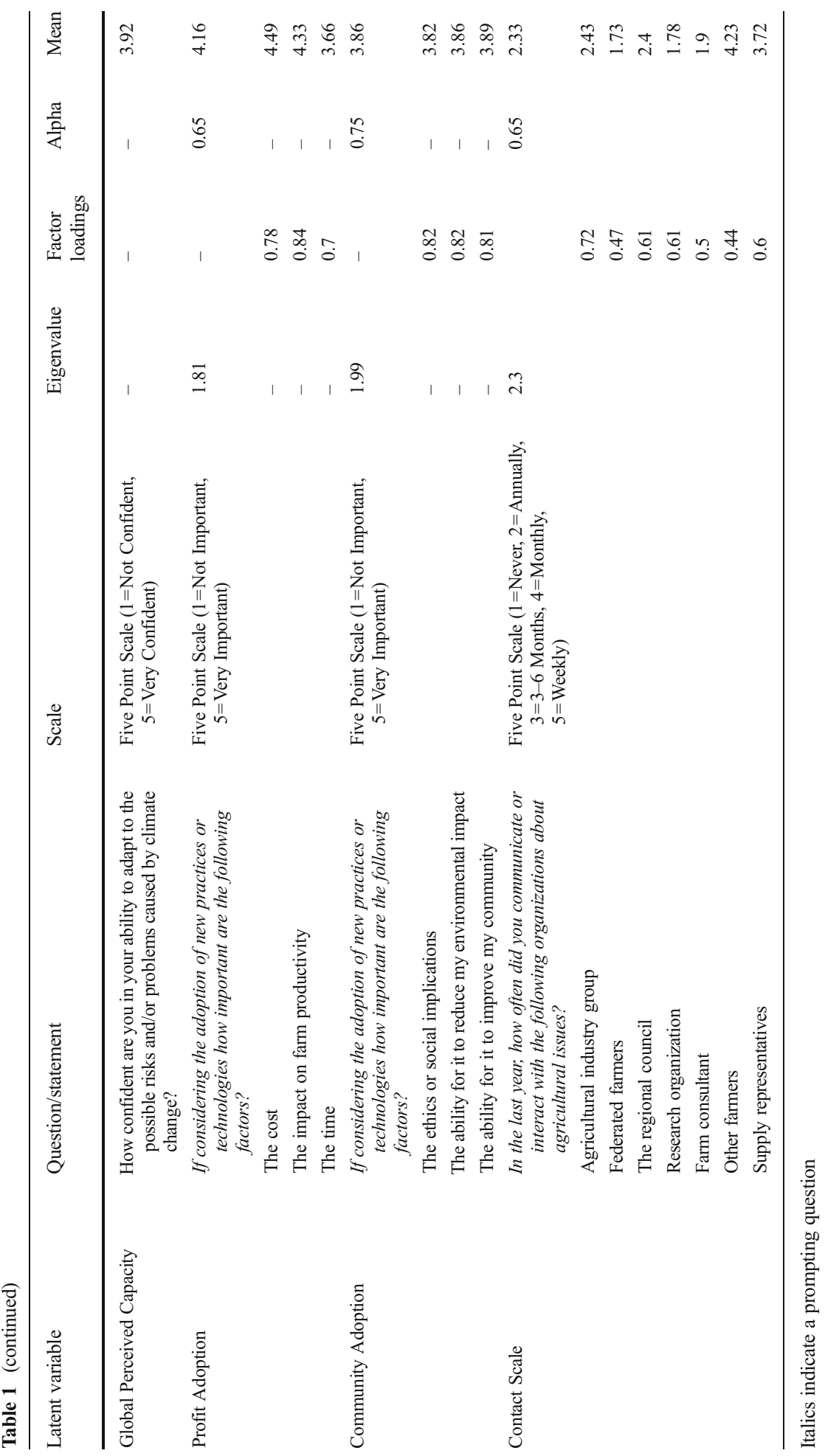


preferences that farmers prioritize when considering a new type of practice. Community Adoption is a measure of the environmental, ethical, and community perceived benefits that farmers prioritize when considering new practices. We also considered age, gender, education level, full-time status, number of hectares managed, presence of a farm succession plan, and organic/biodynamic certification.

We had four dependent variables. Potential Adaptation Adoption measures the overall willingness of farmers to potentially adopt six climate adaptation behaviors in the future. Potential Mitigation Adoption measures the overall willingness of farmers to adopt eight mitigation behaviors in the future. In addition to these two scales, we also had two dependent variables that measured actual adoption of adaptation and mitigation behavior. All adaptation and mitigation practices we include in our models were asked to all farmers; additional practices relevant to specific industries were also asked but are excluded from this analysis because it significantly reduces the sample size and statistical power. Actual Adaptation Adoption and Actual Mitigation Adoption were developed as count variables based on the total number of actual adaptation (six) or mitigation (eight) practices a farmer has already adopted. To determine the reliability of our scales based on factor analysis we utilized a Cronbach's alpha with all scales achieving higher than or equal to 0.65 , an acceptable score (Nunnally 1978). We used four separate linear regression models to test our hypotheses to determine whether similar factors were correlated with potential adoption versus actual adoption.

\section{Results}

\subsection{Dependent variables}

\subsubsection{Actual and potential adaptation adoption}

Average potential adoption across all six practices was 2.46 (very unlikely $=1$, very likely $=5$, Table 1). Among non-adopters, building water storage facilities was the most likely adaptation strategy (48\% likely or very likely). Other strategies were less popular with water monitoring technologies (38\%), drilling more wells or seeking alternative water sources $(31 \%)$ and pumping more groundwater $(28 \%)$ being the most likely strategies among non-adopters. Among already adopting farmers, water monitoring technologies were the most frequent (35\% implementation). Other practices were less common with participation in a community irrigation scheme $(14 \%)$ and water storage facilities (10\%) being the most adopted practices (Fig. 1).

\subsubsection{Actual and potential mitigation adoption}

On average, likely adoption of mitigation behaviors was 2.75 (Table 1). However, in some instances a majority of non-adopting farmers indicated they would be likely or very likely to implement mitigation behaviors especially installing solar panels and wind turbines $(52 \%)$ and investing in more fuel efficient farm equipment $(50 \%)$. One-third of farmers have already planted trees on low performing areas and $29 \%$ have reduced their nitrogen fertilizer rate. On the contrary, only $2 \%$ are using 
biomass or biofuels on farm and only $8 \%$ have installed solar panels or wind turbines (Fig. 1).

\subsection{Independent variables}

\subsubsection{Climate change concern}

Farmers trended slightly towards belief that humans contributed to climate change (mean $=$ $3.21,1=$ strongly disagree, $5=$ strongly agree) with $44 \%$ agreeing or strongly agreeing that humans play a role in climate change (Table 1).

\subsubsection{Biophysical concerns}

Farmers were on average somewhat concerned about potential climate-related risks (mean 2.46, 1 = not concerned, 4 = very concerned). Overall, farmers were most concerned about pests and diseases (mean 3.11) and weeds/invasive species (mean 2.74). Water supply changes and increases in severe droughts were both concerning (mean 2.68) followed by changes in rainfall (mean 2.60) and increase in floods (mean 2.41). On the contrary, temperature impacts were less concerning with heat waves being most concerning (mean 2.32), frosts (mean 2.13), increases in warmer temperatures (mean 2.11) and finally decreases in winter chill hours (mean 1.91) (Table 1).

\subsubsection{Environmental policy concerns}

Overall farmers tended to disagree that New Zealand should have an emissions trading scheme, that agriculture should be part of it and that environmental regulations are effective (mean 2.44, 1 strongly disagree, 5 strongly agree). Farmers were in most disagreement about an ETS for New Zealand (mean 2.03) followed by agriculture's inclusion within an ETS (mean 2.15) and were on average neutral about whether environmental regulations were effective (mean 3.06) (Table 1).

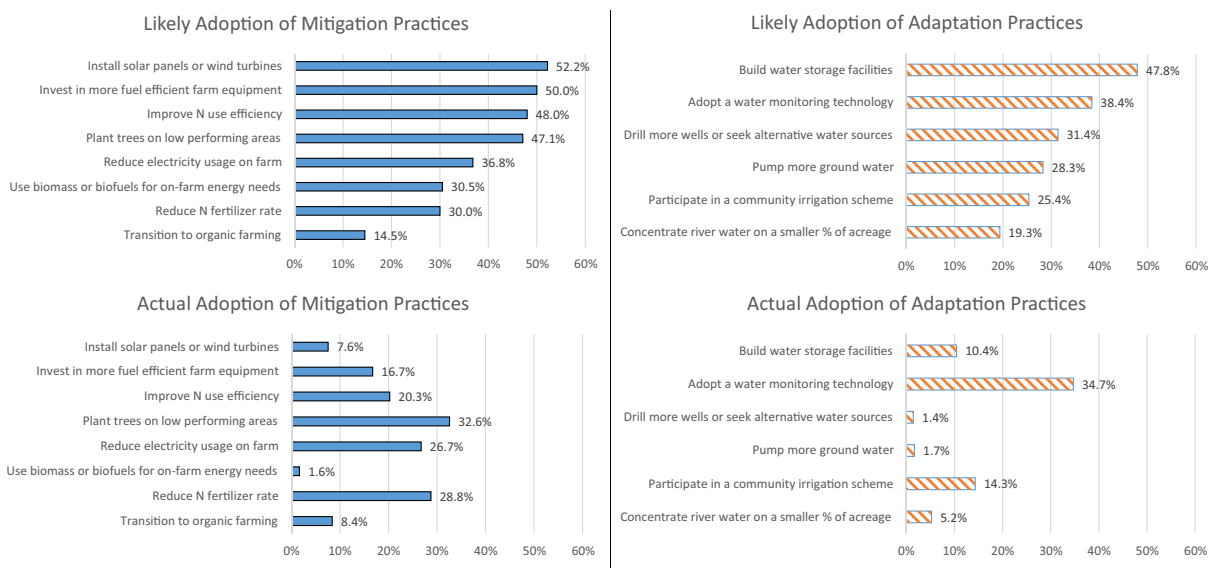

Fig. 1 Farmers' likely and actual adoption of mitigation and adaptation strategies 


\subsubsection{Local and global perceived capacity}

Farmers overall ( 1 not confident, 5 very confident) have confidence in their ability to adapt to climate change (Global Perceived Capacity, mean $=3.92$ ). Nearly $73 \%$ of farmers indicated that they were confident or very confident. On average farmers were less confident in their perceived capacity to reduce their GHGs (Local Perceived Capacity, mean $=3.24$ ) (Table 1). Only $50 \%$ of farmers agreed or strongly agreed that they could reduce their GHGs.

\subsubsection{Profit and community adoption}

On average, profit and cost related factors were of higher concern to farmers than community and other related factors (mean 4.16 and 3.86 respectively on a scale from 1, not important to 5, very important). Average concerns were cost (mean 4.49), farm productivity (mean 4.33), community impact (mean 3.89), environmental impact (mean 3.86), ethical concerns (mean 3.82) and time (mean 3.66) (Table 1).

\subsubsection{Contact scale}

Farmers had a mean of 2.33 on a scale from 1 (never) to 5 (weekly) of contact about agricultural information. Other farmers were the most likely point of contact for agricultural information (mean 4.23) followed by supply representatives (mean 3.72), agricultural industry representatives (mean 2.43), the Regional Council (mean 2.40), farm consultants (mean 1.90), research organizations (mean 1.78) and Federated Farmers (a New Zealand farmer group, mean 1.73) (Table 1).

\subsubsection{Farmer characteristics}

Eighty percent of respondents were older than 45 and $50 \%$ of farmers were over the age of 55 . The majority of respondents were male $(82 \%)$. Farmers had a diversity of formal education- $19 \%$ had a high school diploma while an additional $13 \%$ had some university or apprenticeship training. Thirty-one percent of farmers had a degree from university, technical school or an apprenticeship. The majority (74\%) of farmers were full-time.

\subsubsection{Farm characteristics}

Sixty-eight percent of respondents had acreage in sheep, beef or deer. Twenty nine percent of farmers had acreage in viticulture. Horticulture were $11 \%$ of respondents while cropping/ arable was $8 \%$ of farmers, dairy was $7 \%$ and forestry was $3 \%$ of farm respondents. Since farmers were able to indicate if they had mixed systems, these numbers are not exclusive land types. Average farm size was 427 ha. The majority (52\%) of farmers had some form of a farm succession plan. Seven percent of farms were certified organic or biodynamic.

\subsection{Model results}

Table 2 shows all of the results for our four separate models, which we highlight in additional detail below. 
Table 2 Factors affecting likely and actual adoption of climate practices

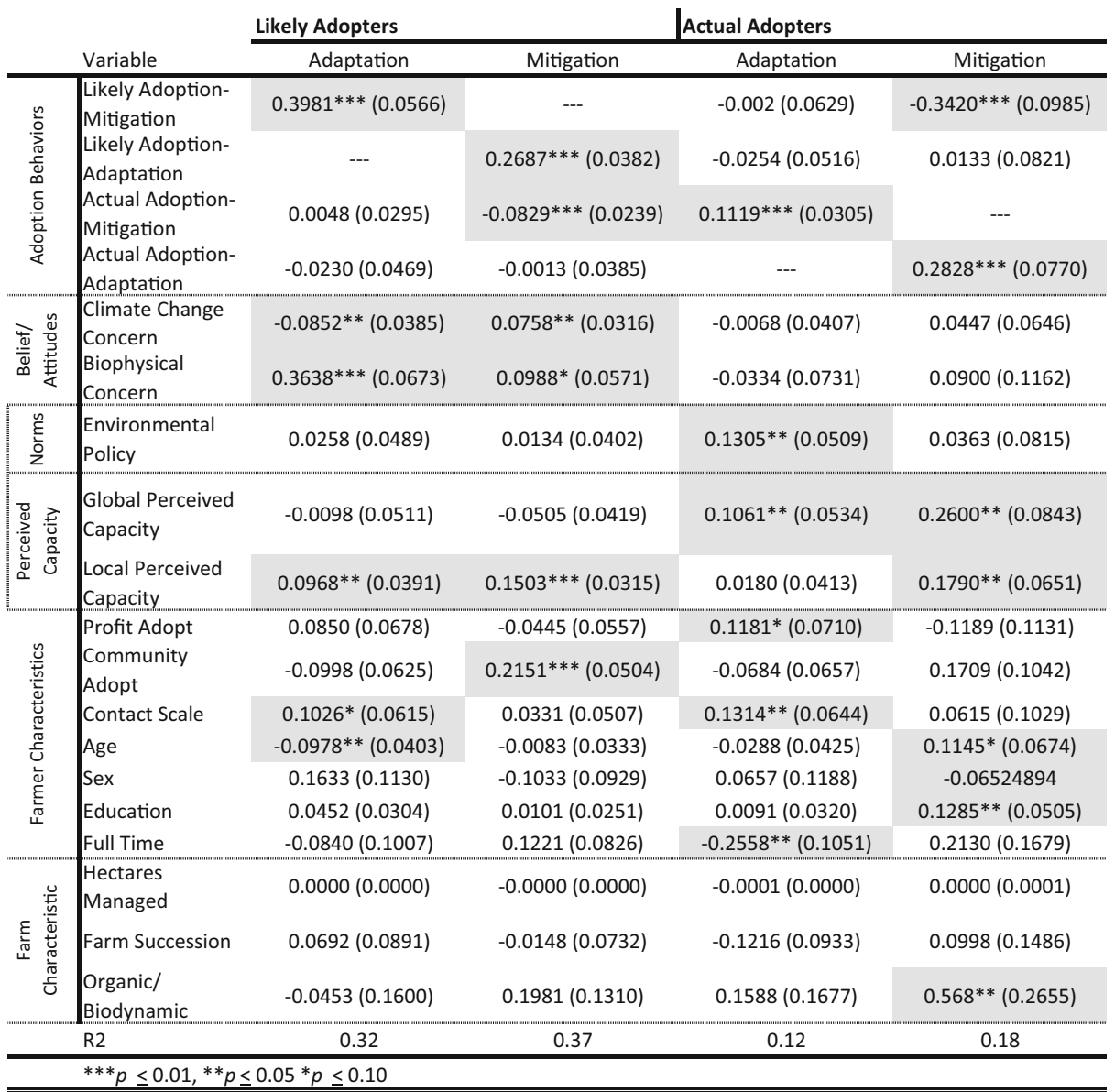

Columns reflect four separate models based on the dependent variable. Variables listed in the rows are independent variables. R2 values reflected at the bottom of each column indicate the total variation explained in each model by the variables considered. Standard errors are listed in parentheses. Shaded boxes indicate significant factors at various $\mathrm{p}$ levels, listed at the bottom of the table

\subsubsection{Likely adoption: adaptation}

Attitudes including belief in human-induced climate change $(p \leq 0.05)$ and concern for biophysical impacts in the future $(p \leq 0.01)$ were significantly correlated with likelihood to adopt adaptation practices (H1). We found no effect of norms on likely adaptation adoption (H2). Local perceived capacity (H3) to reduce emissions was positively associated with increased adoption $(p \leq 0.05)$. Likely adaptation adoption was influenced by farmers who were also likely to adopt mitigation practices $(\mathrm{H} 4)(p \leq 0.01)$. Higher contact with organizations $(p \leq 0.10)$ and older farmers were less likely to indicate they would adopt adaptation behaviors $(p \leq 0.05)$. Model variables explained $32 \%$ of the variance in the dependent variable $\left(\mathrm{R}^{2}=0.32\right)$. 


\subsubsection{Likely adoption: mitigation}

Attitudes were associated with likely mitigation adoption with belief in human-caused climate change $(p \leq 0.05)$ and concern for biophysical impacts $(p \leq 0.10)$ positively associated (H1). We found no effect of norms on likely mitigation adoption (H2). Local perceived capacity to reduce emissions $(p \leq 0.01)$ was significantly associated with likely mitigation adoption (H3). Farmers who indicated likely adaptation practice adoption were more likely to indicate their willingness to adopt mitigation practices in the future $(p \leq 0.01)$. However, farmers who had actually adopted mitigation practices were associated with less likelihood to adopt other mitigation practices in the future $(p \leq 0.01)(\mathrm{H} 4)$. In addition, Community Adopt was also significant $(p \leq 0.01)$, suggesting that farmers who valued community, ethical or environmental issues when considering new practices were more likely to indicate mitigation adoptions. Variables in the model explained $37 \%$ of variance $\left(\mathrm{R}^{2}=0.37\right)$.

\subsubsection{Actual adoption: adaptation}

We found no effect of belief/attitudes for climate change and its risks on adoption (H1). Farmers who had a favorable perception of environmental regulations was positively associated with adaptation behaviors $(p \leq 0.05)(\mathrm{H} 2)$. Global perceived capacity was positively associated with actual adaptation adoption $(p \leq 0.05)(\mathrm{H} 3)$. Actual adoption of adaptation behaviors was not influenced by likely adopters (in other words stated intention to adopt adaptation practices was not associated with actual adoption of adaptation practices). However, actual adopters of mitigation behaviors was significant ( $p \leq 0.01$ ), suggesting that farmers who have already changed behavior in one realm (adaptation) are more likely to also do so in other realms (mitigation) (H4). Level of contact was positively associated with actual adaptation adoption $(p \leq 0.05)$, Profit Adopt was slightly significant $(p \leq 0.10)$ and fulltime farmers were less likely to have adopted adaptation behaviors $(p \leq 0.05)$. Model variables explained $12 \%$ of the variance in the dependent variable $\left(\mathrm{R}^{2}=0.12\right)$.

\subsubsection{Actual adoption: mitigation}

We found that belief/attitudes as well as environmental policy perceptions/norms were not significantly associated with actual mitigation behavior adoption (H1, H2). Both Global Perceived Capacity and Local Perceived Capacity were significantly associated with mitigation adoption $(p \leq 0.05)(\mathrm{H} 3)$. Farmers who had indicated that they would likely adopt mitigation practices was negatively associated with actual adopters of mitigation practices $(p \leq 0.01)$. On the contrary, those who had already adopted adaptation practices were also more likely to have adopted mitigation practices $(p \leq 0.01)$ (H4). Older farmers, women farmers ( $p \leq$ $0.10)$, education and organic farmers $(p \leq 0.05)$ were positively associated with adoption. Overall, model variables explained $18 \%$ of the variance $\left(\mathrm{R}^{2}=0.18\right)$.

\section{Discussion}

\subsection{Discrepancies between potential and actual adoption}

Assessing the potential for adoption of new practices alongside the actual adoption of those practices reveals there are not significant similar factors influencing each. This suggests a 
disconnect between the factors that affect potential and actual adoption and that predictive variables for stated intentions may be different those for actual adoption of CCPs. Relatedly, our work also demonstrates that understanding potential adoption is possible with a higher degree of explanation than understanding actual adoption. At least within our models and the variables we considered, the total variance accounted for with our variables was considerably higher in potential adoption $\left(\mathrm{R}^{2} 0.32-0.37\right)$ versus actual adoption $\left(\mathrm{R}^{2} 0.12-0.18\right)$. This is not necessarily surprising, as it has been well documented that understanding drivers of actual behavior change is complicated and likely includes a variety of factors that are unanticipated (Ajzen et al. 2011), but nevertheless highlights the continued challenge in explaining and assessing human behavior.

\subsection{Factors affecting stated and actual adoption}

For non-adopters we find support for several of our hypotheses and three key factors consistently affecting intended adoption: 1) attitudes and belief (H1);2) local perceived capacity (H3); and 3) the likelihood of intended adoption of the other kind of practice (H4). For actual adopters of practices we find consistent support for only two of our hypotheses: 1) perceived global capacity (H3) (though perceived local capacity was significantly associated with mitigation behaviors) and 2) the actual adoption of other kinds of practices (H4). In only one case is a variable positively associated with both potential and actual adoption: perceived local capacity. This suggests a potential limitation in studies that aim to understand adoption by assessing stated intention. Furthermore the variables that influence stated intention to adopt and actual adoption are significantly different, which we examine in the context of our hypotheses in further detail below.

In line with the TPB, we expected that farmer's belief and attitudes about climate change would influence intention and actual adoption of CCPs (H1). We find partial evidence for this hypothesis. For non-adopters, farmers who believed in human-induced climate change and expressed concerns about its impacts were more likely to indicate they would adopt adaptation and mitigation behaviors. This is consistent with existing studies where farmers with climate belief and risk perceptions were more likely to adopt mitigation and adaptation behaviors (Arbuckle et al. 2013; Haden et al. 2012; Barnes and Toma 2012) and support climate change policies (Niles et al. 2013). Our measure for human-induced climate change ( $44 \%$ belief) also appears to be within the range of other surveys measuring developed world farmer climate perspectives ranging from $25 \%$ in Scotland to $33 \%$ in California to $59 \%$ in the Midwest US to $63 \%$ in Canada (Prokopy et al. 2015; Cox et al. 2015).

That climate change belief and concerns were predictors of potential adoption of CCPs would suggest that one strategy to encourage farmers to adopt CCPs would be to better inform farmers about climate change and its potential risks. Indeed, many existing studies have concluded that increasing information about climate change and its risks may help people better understand the issue and thereby influence their intention to change their behavior (Semenza et al. 2008; Lorenzoni et al. 2007). This "knowledge-deficit" model suggests that people do not act on important issues because they lack the knowledge about the issue, and if given knowledge, will in turn change their behavior (Hansen et al. 2003). However we find climate change belief and risk perceptions are not significant in explaining actual adoption, consistent with more recent perspectives in applying the TPB, in which Ajzen et al. (2011) determine that knowledge has very little influence on actual behavior. Instead, motivation for the behavior is a necessary precursor for actual behavior change consistent with the 
information-motivation-behavioral skills model, in which knowledge and motivation both influence behavior (Fisher et al. 1994; Fisher and Fisher 1992). More recent work found that knowledge does not consistently influence behavior (Misovich et al. 2003) corroborated by other studies in a climate change context such as Kellstedt et al. (2008) who find that climate change knowledge actually makes people less concerned and likely to act.

We find limited evidence for our second hypothesis that subjective norms are important for farmer's likely and actual adoption of CCPs (H2). Unlike in the TPB where Ajzen (1991) makes subjective norms a key component of intended and actual behavior change, we find little evidence this is true in the context of New Zealand farmers and CCPs (only significant for actual adoption of adaptation practices). One explanation for this is the highly polarized political environment for the ETS: only $16 \%$ of our surveyed farmers agreed or strongly agreed that New Zealand should be part of an ETS. This suggests that in contexts in which there is very limited public support for behavior change that subjective norms may not be significant. In essence, if no one else is supporting this or doing it- why should I?

There was a clear role for Local Perceived Capacity and Global Perceived Capacity across all of our models (H3). Local Perceived Capacity had a positive relationship in three out of four of our models including both intended adoptions and actual adoption of mitigation behaviors. Conversely, we find that Global Perceived Capacity is associated only with actual behavior change rather than intended change. This suggests that farmers who have actually changed behavior may be farmers who have a perceived ability to handle broader risks outside the scope of their own control. These results are corroborated by a growing body of work to understand climate change behavior. Broomell et al. (2015) found across a sample of 25 countries perceived capacity was one of the major influences on intention to mitigate emissions. Spence et al. (2011) found that perceived ability to reduce GHGs mediated the relationship between climate experiences and the likelihood of adopting mitigation behaviors among UK citizens. Similarly, Milfont (2012) determined that perceived efficacy was clearly linked with climate belief. Additional studies have demonstrated that perceived capacity or a sense of powerlessness can significantly influence policy support for climate change (Smith and Leiserowitz 2014; Zahran et al. 2006). Fostering a sense of adaptiveness and capacity in farmers may be useful for enabling them to change behavior, though this of course may be hampered by actual capacity to change behavior.

Finally, we expected that farmers who had adopted one type of practice already would be more likely to intend to adopt other practices in the future (H4). Farmers who intend to or have already adopted one type of practice (mitigation or adaptation) also are willing to adopt other types of practices (mitigation or adaptation). Similarly, a farmer who has already adopted an adaptation practice is also more likely to have also already adopted a mitigation practice and vice versa. However, our models find no relationship between farmers who have already adopted adaptation practices and their intention to adopt other adaptation practices in the future. Furthermore, we find farmers who have already adopted mitigation behaviors are actually less likely to indicate that they would adopt other mitigation practices in the future.

It may be the case that farmers believe they have already taken steps to adapt or mitigate their farms or have perhaps invested significant capital into existing practices that prevent adoption of additional practices. These farmers may therefore not feel that they need to adopt additional mitigation or adaptation practices. However, out of the total eight mitigation behaviors, $90 \%$ of farmers had adopted 3 or fewer behaviors, with $60 \%$ adopting one or no practices. For adaptation, $53 \%$ of farmers had adopted none of the practices with another $32 \%$ adopting only one practice. Ninety-five percent of surveyed farmers had adopted 2 or 
fewer practices. In short, there are many other practices that most farmers could adopt in the future.

Another, and likely more compelling explanation, is that adoption has not actually been done so for climate reasons. This reality is corroborated by evidence from our models that climate change belief and concerns were a significant predictor for stated intention to adopt practices but not for actual adoption of practices. Thus, farmers who have actually changed their behaviors have not necessarily done so for potential mitigation and adaptation benefits or because they are concerned about climate change for the future. This is also evidenced through the importance of profit in the adoption of actual adaptation practices- it may be the case that farmers have mostly adopted these adaptation strategies for reasons related to their own productivity, cost and time concerns. In this same vein, we recognize that these practices all have varying levels of potential benefits and costs that may confer different tradeoffs for farmers and influence their potential adoption.

\subsection{Demographics and farm characteristics inconsistent}

Finally, despite our attempts to test a variety of farmer and farm characteristics, we find no consistent predictors for both stated behavior change and actual adoption. In fact, we find contradictory evidence in that age is a negative predictor of likelihood to adopt adaptation behaviors but a positive predictor of actual adoption of mitigation behaviors. This is consistent with the literature on adoption of innovations, which has found that there are no universal predictors for adoption (Knowler and Bradshaw 2007; Prokopy et al. 2008). This indicates that all types of farmers are potentially open to considering the adoption CCPs and that assumptions about certain demographics or farm types and behavioral change are not warranted.

\section{Conclusion}

There is evidence across a wide range of disciplines that human intention to do something does not always indicate that they will. It is important to better assess and empirically understand why these discrepancies exist and what factors influence intention and actual behavior. For an issue like climate change this is particularly timely since many policies and programs are being implemented and accurate understanding of what motivates real change in behavior is useful for effective design. Amongst our key findings is that beliefs/attitudes towards an issue is not significantly associated with behavior change in our context. This is consistent with the TPB in its more recent applications (Ajzen et al. 2011) and suggests for scientists that continuing to state facts about climate change in hopes that it will change people's behaviors is not necessarily impactful. Instead, fostering a sense of capacity and confidence for people to be able to change their behavior is crucial for both intention and actual adoption. This can help people overcome a sense of powerlessness that may be particularly acute for a collective action problem like climate change. Theoretically, we also demonstrate that the TPB may not hold up in contexts where there is an overwhelming sense that subjective norms are not important. The fact that so many farmers didn't feel that it was necessary to have an ETS meant that this variable was not an accurate predictor of adoption. 
This paper demonstrates a disconnect between intention and actual behavior related to CCPs, suggesting that additional studies are necessary. Though challenging to implement given funding restrictions and grant time-frames for academic research, longitudinal data will be more compelling to understand intention and actual behavior change. The work of the Climate Change, Agriculture, and Food Security (CCAFS) program of the CGIAR is one positive step forward in this direction. Nevertheless, if we seek to design effective policies and interventions for climate change that involves individual behaviors, such data will be crucial for their design, and should be prioritized for future studies.

Acknowledgments Funding from the US National Science Foundation (NSF) Graduate Research fellowship, US NSF IGERT grant - DGE\#0801430, the New Zealand Foundation for Research, Science and Technology, and AgResearch. We thank Mark Lubell and all of the farmers and stakeholders who participated in the project through interviews and surveys.

Open Access This article is distributed under the terms of the Creative Commons Attribution 4.0 International License (http://creativecommons.org/licenses/by/4.0/), which permits unrestricted use, distribution, and reproduction in any medium, provided you give appropriate credit to the original author(s) and the source, provide a link to the Creative Commons license, and indicate if changes were made.

\section{References}

Ajzen I (1991) The theory of planned behavior. Organ Behav Hum Decis Process 50:179-211

Ajzen I, Joyce N, Sheikh S, Cole NG (2011) Knowledge and prediction of behavior: the role of information accuracy in the theory of planned behavior. Basic Appl Soc Psychol 33:101-117

Arbuckle JG, Morton LW, Hobbs J (2013) Farmer beliefs and concerns about climate change and attitudes toward adaptation and mitigation: evidence from Iowa. Clim Chang 118:551-563

Arbuckle JG, Hobbs J, Loy A, Wright Morton L, Prokopy LS, Tyndall J (2014) Understanding farmer perspectives on climate change: toward effective engagement strategies for adaptation and mitigation in the Corn belt. J Soil Water Conserv 69:505-516

Bandura A (1986) Social foundations of thought and action: a social cognitive theory. Prentice-Hall, Englewood Cliffs

Barham BL (1996) Adoption of a politicized technology: bST and Wisconsin dairy farmers. Am J Agric Econ 78: $1056-1063$

Barham BL, Foltz JD, Jackson-Smith D, Moon S (2004) The dynamic of agricultural biotechnology adoption: lessons from rBST use in Wisconsin, 1994-2001. Am J Agric Econ 86:61-72

Barnes AP, Willock J, Hall C, Toma L (2009) Farmer perspectives and practices regarding water pollution control programmes in Scotland. Agric Water Manag 86:1715-1722

Barnes A, Toma L (2012) A typology of dairy farmer perceptions towards climate change. Climatic Change 112(2):507-522 doi:10.1007/s10584-011-0226-2

Broomell SB, Budescu DV, Por H (2015) Personal experience with climate change predicts intentions to act. Glob Environ Chang 32:67-73

Bryan E, Deressa TT, Gbetibouo GA, Ringler C (2009) Adaptation to climate change in Ethiopia and South Africa: options and constraints. Environ Sci Policy 12:413-426

Bullock D (2012) Emissions trading in New Zealand: development challenges and design. Environ Polit 21:657675

Challinor AJ, Watson J, Lobell DC, Howden SM, Smith DR, Chettri N (2014) A meta-analysis of crop yield under climate change and adaptation. Nat Clim Chang 4:287-291

Clark AJ, et al. (2012) Impacts of climate change on land-based sectors and adaptation options. In: Clark AJ, Nottage RAC, Hansford D (eds). Stakeholder report to the sustainable land management and climate change adaptation technical working group. Ministry for Primary Industries. $76 \mathrm{p}$

Contant CK, Korsching PF (1997) Farmers' commitment to continued use of the late spring soil nitrogen test. Am J Altern Agric 12:20-27

Costello AB, Osborne JW (2005) Best practices in exploratory factor analysis: Four recommendations for getting the most from your analysis. Pract Assess Res Eval 10

Cox, Gardner, Fraser (2015) A survey-based assessment of cattle producers' adaptation to climate change in British Columbia, Canada. Rangel Ecol Manag 68:119-130 
Delgado JA, Bausch WC (2005) Potential use of precision conservation techniques to reduce nitrate leaching in irrigated crops. J Soil Water Conserv 60:379-387

Fickling D (2003) Farmers raise stink over New Zealand 'fart tax'. The Guardian. September 4 2003. http://www. theguardian.com/world/2003/sep/05/australia.davidfickling

Fisher JD, Fisher WA (1992) Changing AIDS-risk behavior. Psychol Bull 111:455-474

Fisher JD, Fisher WA, Williams SS, Malloy TE (1994) Empirical tests of an information-motivation-behavioral skills model of AIDS-preventative behavior with gay men and heterosexual university students. Health Psychol 13:238-250

Fuglie KO, Kascak CA (2001) Adoption and diffusion of natural-resource-conserving agricultural technology. Rev Agric Econ 23:386-403

Garb Y, Friedlander L (2014) From transfer to translation: using systemic understandings of technology to understand drip irrigation uptake. Agric Syst 128:13-24

Greiner R, Gregg D (2011) Farmers' intrinsic motivations, barriers to the adoption of conservation practices and effectiveness of policy instruments: Empirical evidence from northern Australia Land Use Policy 28(1):257265 doi:10.1016/j.landusepol.2010.06.006

Haden VR, Niles MT, Lubell M, Perlman J, Jackson L (2012) Global and local concerns: What attitudes motivate farmers to mitigate and adapt to climate change. PLOS One 7

Hansen J, Holm L, Frewer L, Robinson P, Sandøe P (2003) Beyond the knowledge deficit: recent research into lay and expert attitudes to food risks. Appetite 41:111-121

Jackson LE, Haden VR, Hollander AD, Lee H, Lubell M, Mehta VK, O’Geen T, Niles M, Perlman J, Purkey D, Salas W, Sumner D, Tomuta M, Dempsey M, Wheeler SM (2012). Adaptation strategies for agricultural sustainability in Yolo County, California California Energy Commission p. 206

Kellstedt PM, Zahran S, Vedlitz A (2008) Personal efficacy, the information environment and attitudes toward global warming and climate change in the United States. Risk Anal 28:113-126

Knowler D, Bradshaw B (2007) Farmers' adoption of conservation agriculture: a review and synthesis of recent research. Food Policy 32:25-48

Kristjanson P, Neufeldt H, Gassner A, Mango J, Kyazze FB, Desta S, Sayula G, Thiede B, Forch W, Thornton PK, Coe R (2012) Are food insecure smallholder households making changes in their farming practices? Evidence from East Africa. Food Secur 4:381-397

Lorenzoni I, Nicholson-Cole S, Whitmarsh L (2007) Barriers perceived to engaging with climate change among the UK public and their policy implications. Glob Environ Chang 17:445-459

Milfont TL (2012) The interplay between knowledge, perceived efficacy, and concern about global warming and climate change: a one-year longitudinal study. Risk Anal 32:1003-1020

Ministry for Environment (2008) Climate change effects and impacts assessment. A guidance manual for local government in New Zealand. 2nd Edition. Prepared by Mullan, B., Wratt, D., Dean, S., Hollis, M., Allan, S., Williams, T., Kenny, G. National Institute for Water and Atmosphere Client Report WLG2007/62. 156p

Ministry for the Environment (2013). New Zealand greenhouse gas inventory 1990-2011

Misovich SJ, Martinez T, Fisher JD, Bryan A, Catapano N (2003) Predicting breast self-examination: a test of the information-motivation-behavioral skills model. J Appl Soc Psychol 33:775-790

National Institute for Water and Atmosphere (2008) Climate change projections for New Zealand. http://www. niwa.co.nz/sites/default/files/import/attachments/IPCC 08 report 02 s.pdf

Niles MT, Lubell M, Haden VR (2013) Perceptions and responses to climate policy risks among California farmers. Glob Environ Chang 23:1752-1760

Niles MT, Lubell M, Brown M (2015) How limiting factors drive agricultural adaptation to climate change. Agric Ecosyst Environ 200:178-185

Nunnally JC (1978) Psychometric theory. McGraw-Hill, New York

Prokopy LS, Floress K, Klotthor-Weinkauf D, Baumgart-Getz A (2008) Determinants of agricultural best management practice adoption: evidence from the literature. J Soil Water Conserv 63:300-311

Prokopy L, Arbuckle JG, Barnes A, Haden VR, Hogan A, Niles M, Tyndall J (2015) Farmers and climate change: a cross-national comparison of beliefs and risk perceptions in high-income countries. Environ Manag 56:492-504

Reimer AP, Gramig BM, Prokopy LS (2013) Farmers and conservation programs: explaining differences in environmental quality incentives program applications between states. J Soil Water Conserv 68:110-119

Rogers EM (2003) Diffusion of innovations, 5th edn. Simon and Schuster, Inc, New York

Ryan B, Gross NC (1943) The diffusion of hybrid seed corn in two Iowa communities. Rural Sociol 8:15

Semenza JC, Hall DE, Wilson DJ, Bontempo BD, Sailor DJ, George LA (2008) Public perception of climate change: voluntary mitigation and barriers to behavior change. Am J Prev Med 35:479-487

Seo SN, Mendelsohn R (2008) An analysis of crop choice: adaptating to climate change in South American farms. Ecol Econ 67:109-116 
Smith N, Leiserowitz A (2014) The role of emotion in global warming policy support and opposition. Risk Anal 34:937-948

Smith PM et al (2014) Agriculture, Forestry and Other Land Use (AFOLU). In: Edenhofer O et al (eds) Climate change 2014: mitigation of climate change, Contribution of working group III to the fifth assessment report of the intergovernmental panel on climate change. Cambridge University Press, Cambridge

Spence A, Poortinga W, Butler C, Pidgeon NF (2011) Perceptions of climate change and willingness to save energy related to flood experience. Nature Clim Change 1(1):46-49 Retrieved from doi:10.1038/ nclimate 1059

Wood SA, Jina AS, Jain M, Kristjanson P, DeFries RS (2014) Smallholder farmer cropping decisions related to climate variability across multiple regions. Glob Environ Chang 25:163-172

Zahran S, Brody SD, Grover H, Vedlitz A (2006) Climate change vulnerability and policy support. Soc Nat Resour 19:771-789 